\title{
Dual Colorimetric Sensor for
} $\mathrm{Hg}^{2+} / \mathrm{Pb}^{2+}$ and an Efficient Catalyst Based on Silver Nanoparticles Mediating by the Root Extract of Bistorta amplexicaulis

\author{
Farid Ahmed ${ }^{1,2}$, Humaira Kabir ${ }^{3}$ and Hai Xiong ${ }^{1 *}$ \\ ${ }^{1}$ Institute for Advanced Study, Shenzhen University, Shenzhen, China, ${ }^{2}$ College of Physics and Optoelectronic Engineering, \\ Shenzhen University, Shenzhen, China, ${ }^{3}$ Department of Chemistry, Women University of Azad Jammu and Kashmir, Bagh, \\ Pakistan
}

Environmental pollution derivated from toxic metals and organic toxins is becoming a serious issue worldwide because of their harmful effects on the ecosystem and human health. Here we are reporting an extremely selective and cost-effective colorimetric sensor for simultaneous recognition of $\mathrm{Hg}^{2+}$ and $\mathrm{Pb}^{2+}$ by using green synthesized silver nanoparticles (AgNPs) mediated from the environmental friendly roots extract of Bistorta amplexicaulis. Biogenic synthesized AgNPs were well-characterized by various spectroscopic techniques e.g., UV-vis, FT-IR, XRD, AFM, and Zetasizer. The photophysical potential of synthesized AgNPs toward common metal cations was explored via absorption spectroscopy and colorimetric assay. The hypsochromic shift in the SPR band of AgNPs can easily be detected through naked eyes vision from dark brown to light yellow in the case of $\mathrm{Hg}^{2+}$. A substantial reduction in the absorbance of AgNPs was recorded upon mixing with $\mathrm{Pb}^{2+}$. AgNPs based colorimetric sensor is highly sensitive toward $\mathrm{Hg}^{2+}$ and $\mathrm{Pb}^{2+}$ with a limit of detection (LOD) of $8.0 \times 10^{-7} \mathrm{M}$ and $2.0 \times 10^{-7} \mathrm{M}$ for $\mathrm{Hg}^{2+}$ and $\mathrm{Pb}^{2+}$, respectively. Furthermore, AgNPs showed promising catalytic activity for the degradation of methyl orange dye. These results demonstrate that Bistorta amplexicaulis stabilized silver nanoparticles have potential applications as a colorimetric sensor and an effective catalyst for the degradation of methyl orange.

Keywords: colorimetric sensor, green synthesis, silver nanoparticles, catalyst, Bistorta amplexicaulis

\section{HIGHLIGHTS}

Received: 05 August 2020 Accepted: 11 September 2020 Published: 22 October 2020

Citation:

Ahmed F, Kabir H and Xiong H (2020) Dual Colorimetric Sensor for $\mathrm{Hg}^{2+} / \mathrm{Pb}^{2+}$ and an Efficient Catalyst Based on Silver Nanoparticles Mediating by the Root Extract of Bistorta amplexicaulis.

Front. Chem. 8:591958. doi: 10.3389/fchem.2020.591958

- A highly selective and an inexpensive colorimetric sensor for the detection of $\mathrm{Hg}^{2+}\left(1 \times 10^{-6}\right.$ to $\left.1 \times 10^{-7} \mathrm{M}\right)$ and $\mathrm{Pb}^{2+}\left(1 \times 10^{-6}\right.$ to $\left.1 \times 10^{-8} \mathrm{M}\right)$ with good linearity was developed by using AgNPs synthesized from Bistorta amplexicaulis (root extract).

- AgNPs as colorimetric sensor offer qualitative and quantitative information by naked-eye visibility without using expensive equipment.

- Utilization of plant extract due to its simplicity, non-toxicity, easy availability, relative reproducibility, eco-friendly, low cost, and higher effectiveness. It also does not require intense maintenance of laboratory cultures for nanoparticles synthesis.

- Silver nanoparticles mediating by Bistorta amplexicaulis were found to be highly effective catalyst for the degradation of methyl orange dye. 


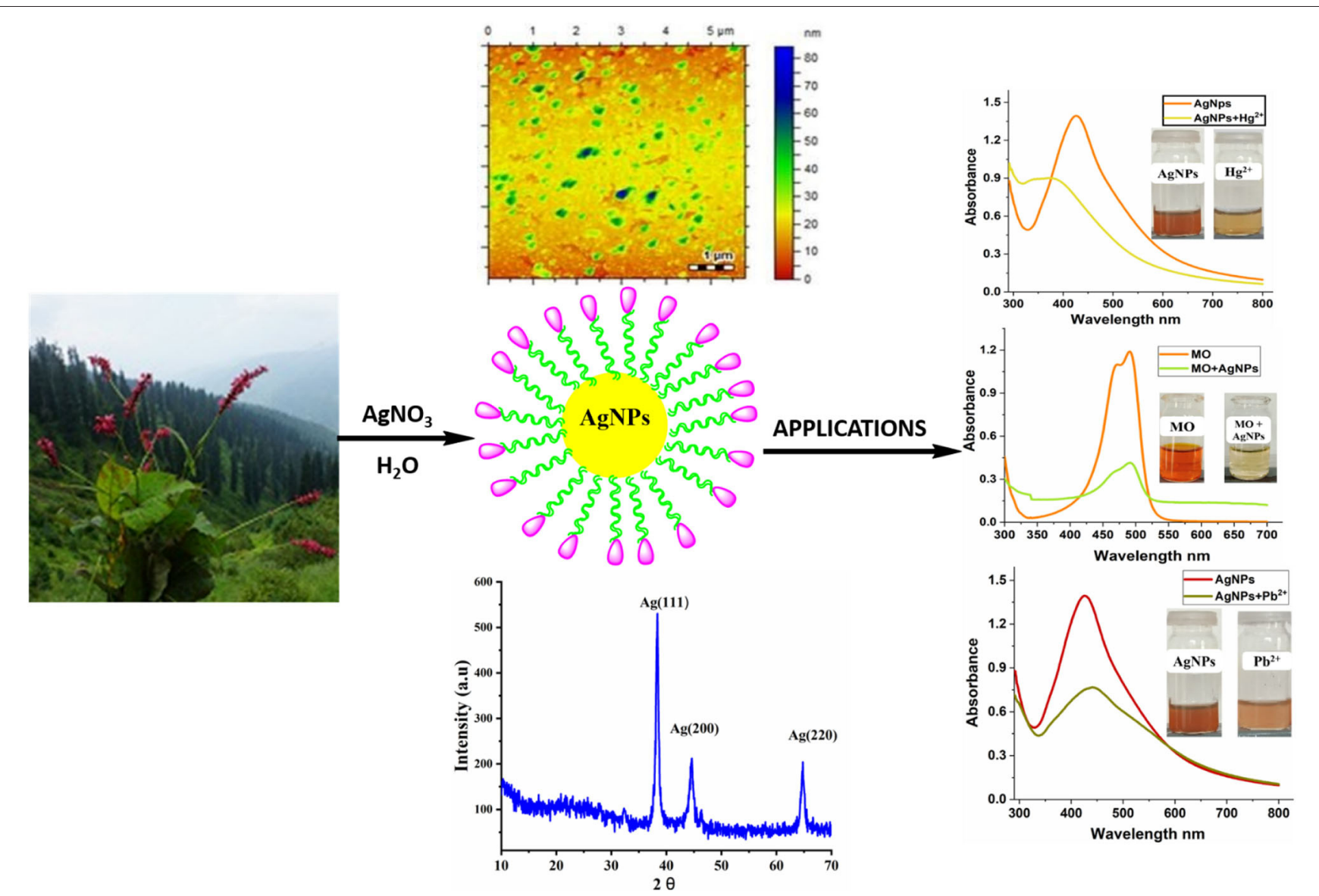

GRAPHICAL ABSTRACT | Green synthesized AgNPs were found to be excellent dual colorimetric sensor for $\mathrm{Hg}^{2+}$ and $\mathrm{Pb}^{2+}$ with a limit of detection of 0.8 and $0.2 \mu \mathrm{M}$, respectively. AgNPs as colorimetric sensor offer qualitative and quantitative information by naked-eye visibility without using expensive equipment.

\section{INTRODUCTION}

Environmental contamination due to heavy metals and organic dyes is becoming a serious issue worldwide due to their harmful effects on the ecosystem and human health (Duruibe et al., 2007). Heavy metals like cadmium, lead, nickel, chromium, and mercury are significant environmental contaminants in regions with high phylogeny pressure even in trace amounts (Waseem et al., 2014; Paz et al., 2019). Amongst various heavy metal ions, mercury is one of the most toxic metals for human and aquatic life. Elemental mercury and its methyl derivatives are not biodegradable and pose devastating effects on animal and human bodies, which can damage DNA, prevent ligand-receptor binding, damage kidney, liver, disturb the immune system, and even can cause death (Rurack and Resch-Genger, 2002; Ziemba et al., 2006; Hong-Xin et al., 2017). Lead is also considered as extremely toxic metal ions and can cause different health problems in human beings especially in children, senses to epilepsy, unconsciousness, kidney let-down, and even expiry (Papanikolaou et al., 2005; Dooyema et al., 2012). In environment $\mathrm{Pb}^{2+}$ in any form cause harms to crops, soil, water, air, and other edible material (Wang et al., 2006). Other organic pollutants also had an adverse effect on human health beside heavy metal ion. About $20 \%$ of freshwater pollution has been estimated due to industrial waste containing unconsumed dyes and traces of metal ions. Purification of wastewater using novel environmentally friendly methods is becoming a hot research topic from the last few decades (Yu et al., 2017; Bolisetty et al., 2019).

Several classical methods are reported in the literature for the selective detection of $\mathrm{Hg}^{2+}$ and $\mathrm{Pb}^{2+}$, including atomic absorption spectrometry, ICP-MS method (Karunasagar et al., 1998; Fong et al., 2007), GC-atomic fluorescence (Nevado et al., 2005), HPLC (Kodamatani et al., 2012), Fluorescence sensor (Chang et al., 2007; Chiang et al., 2008), conjugated polymers (Liu et al., 2007), ratiometric (Yarur et al., 2019), oligonucleotides (Ono and Togashi, 2004; Lin et al., 2011; Lu et al., 2013), proteins (Guo and Irudayaraj, 2011), bioluminescent bacterial sensors (Durand et al., 2015), and electrochemical sensing (Zhu et al., 2017) etc. All the above-mentioned methods used expensive instrumentation, time-consuming sample preparation steps, and more laborious. There is a growing interest for quick on-site analysis with sensors that are capable of distinguishing heavy metal ions on a real-time basis. In this regard, colorimetric sensors have attracted particular consideration for offering 
qualitative and quantitative information by naked-eye visibility without using sophisticated equipment (Tang and Li, 2017; Choudhary et al., 2020; Kateshiya et al., 2020). Noble metal nanoparticles (AuNPs, AgNPs) are extensively used in the field of sensing and biosensing due to their exceptional optical properties. Silver nanoparticles (AgNPs) have gained remarkable attention in the area of colorimetric sensors because of their distinctive properties (Farhadi et al., 2012; Wang et al., 2012; Jarujamrus et al., 2015; Singh R.K. et al., 2018; ul Ain et al., 2019). Silver nanoparticle exhibits a high excitation coefficient and specific optical properties in the visible region. Conventionally nanoparticles were synthesized by physical and chemical methods. The chemical synthesis of AgNPs contributes a number of the disadvantages like use to reducing agents, harmful chemical adsorbs on the external surface of NPs having damaging effects in the pharmaceutical applications. Alternatively, green synthesis of NPs using root and leaf exact of plants has gained much interest due to an environmentfriendly approach (Dhand et al., 2016; Jebril and Dridi, 2020). The utilization of root and leaf extract of plants has shown to be better methods because of slower kinetics, economical, eco-friendly, and fewer biohazards (Wang et al., 2014; Veisi et al., 2018). The phytochemicals present in plant extracts such as protein, amino acid, polyphenols, carbohydrates etc. may act as reducer and stabilization agents in the synthesis of biogenic silver nanoparticles (Gomathi et al., 2020). The presence of diverse functional groups in the capping facilitates the binding of metal ion on to the surface of silver nanoparticles. A different part of plant extracts (fruit, flower, leaves, and root) can be used to reduce and stabilize the metal/metal oxide nanoparticles in the "one-pot" synthesis method. Due to the tunable size and distance-dependent optical properties of metallic nanoparticles, they have been preferably used for the recognition of heavy metal ions in contaminated water systems (Annadhasan et al., 2014). Many researchers have used a green synthesis approach for the synthesis of metal/metal oxide nanoparticles via plant leaf extracts to further explore their various applications (Koduru et al., 2018). The advantages of using metal NPs as colorimetric sensors for heavy metal ions in environmental systems/samples include simplicity, costeffectiveness, and high sensitivity at sub-ppm levels. Plant extracts stabilized AgNPs and AuNPs are used as colorimetric probe for the recognition of heavy metal ions (cadmium, mercury, lead, chromium etc.) in water (Singh J. et al., 2018).

Here we are reporting the biogenic synthesis of AgNPs using Bistorta amplexicaulis root extract for the colorimetric recognition of $\mathrm{Hg}^{2+}$ and $\mathrm{Pb}^{2+}$ ion for the first time. Biogenic AgNPs were characterized by using UV-visible, FTIR, XRD, AFM, and Zetasizer analysis. The photophysical potential of NPs was studied using UV-visible spectroscopy and colorimetric assay. Newly synthesized AgNPs were found to be a highly selective colorimetric sensor for $\mathrm{Hg}^{2+}$ and $\mathrm{Pb}^{2+}$ even in the presence of several competitive metal ions. The catalytic activity of nanoparticle was also evaluated which revealed that AgNPs could be used as a catalyst for the degradation of methyl orange.

\section{EXPERIMENTAL SECTION}

\section{Martials and Methods}

Roots of Bistorta amplexicaulis plant was collected from Ghangachoti Bagh Azad Kashmir. Chemicals including $\mathrm{AgNO}_{3}$, $\mathrm{NaNO}_{3}, \mathrm{KCl}, \mathrm{CaCl}_{2}, \mathrm{SnCl}_{2}, \mathrm{BaCl}_{2} \cdot 2 \mathrm{H}_{2} \mathrm{O}, \mathrm{HgCl}_{2}, \mathrm{PbCl}_{2}, \mathrm{CuSO}_{4}$, $\mathrm{Mg}\left(\mathrm{NO}_{3}\right)_{2}, \mathrm{Ni}\left(\mathrm{NO}_{3}\right)_{2} \cdot 6 \mathrm{H}_{2} \mathrm{O}, \mathrm{AlCl}_{3}$, and $\mathrm{CuSO}_{4} \cdot 5 \mathrm{H}_{2} \mathrm{O}$ were purchased from chemical companies i.e., Merck or Sigma Aldrich and used without any further pretreatment. A calculated amount of $\mathrm{AgNO}_{3}$ and each metal salt were added in distilled water to prepare a stock solution.

\section{Preparation of Plant Extract}

Plants' roots were carefully washed three times with deionized water to remove the dust particles and dried in shadow then grinded to a fine powder. After that $5 \mathrm{~g}$ roots powder of Bistorta amplexicaulis was socked in $100 \mathrm{~mL}$ of $\mathrm{H}_{2} \mathrm{O}$ and stirred for $1 \mathrm{~h}$ at $25^{\circ} \mathrm{C}$. Subsequently, the mixture was filtered via normal filter paper, and obtained root extract solution was used for nanoparticle synthesis.

\section{Biogenic Preparation of AgNPs}

Nanoparticles were synthesized using a green chemistry approach without using any toxic reducing or capping agents. For the preparation of Bistorta amplexicaulis stabilized AgNPs plant extract solution and $\mathrm{AgNO}_{3}(1 \mathrm{mM})$ solution was mixed in various ratios $(1: 1,1: 5$, and $1: 10 \mathrm{v} / \mathrm{v})$, and resulted mixture was stirred at $25^{\circ} \mathrm{C}$ for $30 \mathrm{~min}$. The formations of nanoparticles were examined by the color change of the solution. Different parameters related to the synthesis and stability of nanoparticles was also optimized.

\section{Characterization of Nanoparticles}

UV-visible spectrophotometer-1800 (Shimadzu, Japan) was used for the characterization and sensing application of AgNPs. The shape and average size of AgNPs were dogged through Agilent 5500 atomic force microscope (AFM). Crystalline nature of synthesized NPs was studied by XRD analysis using Xray diffractometer (Shimadzu, XRD-6000). FTIR spectrum was recorded utilizing $\mathrm{KBr}$ discs method by using FTIR BrukerEQUINOX-55 at encompassing conditions.

\section{General Procedures for Sensing Experiments}

The sensing potential of the synthesized nanoparticles toward metal cations was explored using UV-visible spectroscopy. Generally, $1 \mathrm{~mL}$ solution of nanoparticles was mixed with $1 \mathrm{~mL}$ solution of different metal ions $(100 \mu \mathrm{M})$ at $25^{\circ} \mathrm{C}$. Colorimetric response and alteration in absorption intensity were examined using UV-visible spectroscopy. A detailed procedure for different sensing experiment is provided in the Supplementary Information.

\section{Tap Water Experiments}

Tap water samples were collected from the chemistry lab of Women University Bagh Azad Kashmir Pakistan and were used without filtration. Tap water samples were spiked with a known concentration of $\mathrm{Hg}^{2+}(100 \mu \mathrm{M})$ and $\mathrm{Pb}^{2+}(100 \mu \mathrm{M})$. 
Nanoparticles solution was mixed with $\mathrm{Hg}^{2+}$ and $\mathrm{Pb}^{2+}$ solution (prepared in tap water) under similar experimental conditions and the changes in the absorption spectrum were recorded.

\section{General Procedures for the Degradation of Methyl Orange Dye}

For degradation experiments, $5 \mathrm{~mL}$ of methyl orange solution $(0.1 \mathrm{mM})$, a fixed amount of silver nanoparticles $(1 \mathrm{mg})$ were mixed to stir at room temperature. The degradation of methyl orange was checked by time-based UV-visible spectra. The sample was stirred for maintaining the equilibrium of the working solution and recorded UV- spectra before and after stirring. Before stirring at " 0 " time, the first reading was taken and then placed the sample for stirring to observe the color change at different times. Then UV- visible spectra of these samples were recorded and calculate a standard error of each reading.

\section{RESULTS AND DISCUSSION}

\section{Characterization of AgNPs}

Bistorta amplexicaulis stabilized AgNPs were characterized via various spectroscopic techniques including UV-visible, XRD, AFM, Zetasizer, and FTIR. Silver nanoparticles contained distinctive optical properties in which they interact strongly with specific wavelengths of light. Electrons move freely in AgNPs because the difference between valence and conduction band is minimum. Due to these free electrons, surface plasmon resonance (SPR) absorption band is formed. The SPR band formation is because of the collective oscillation of AgNPs and electrons are in resonance with light waves (Zhang et al., 2016). Bistorta amplexicaulis stabilized silver NPs showed characteristic nanosized particles band at $427 \mathrm{~nm}$ as shown in Figure 1A. Carbohydrates, amino acid, and polyphenolic compounds present in the aqueous extracts of Bistorta amplexicaulis perform a dual role as reductant along with capping agents in the stabilization of AgNPs (Supplementary Table 1). Phenolic
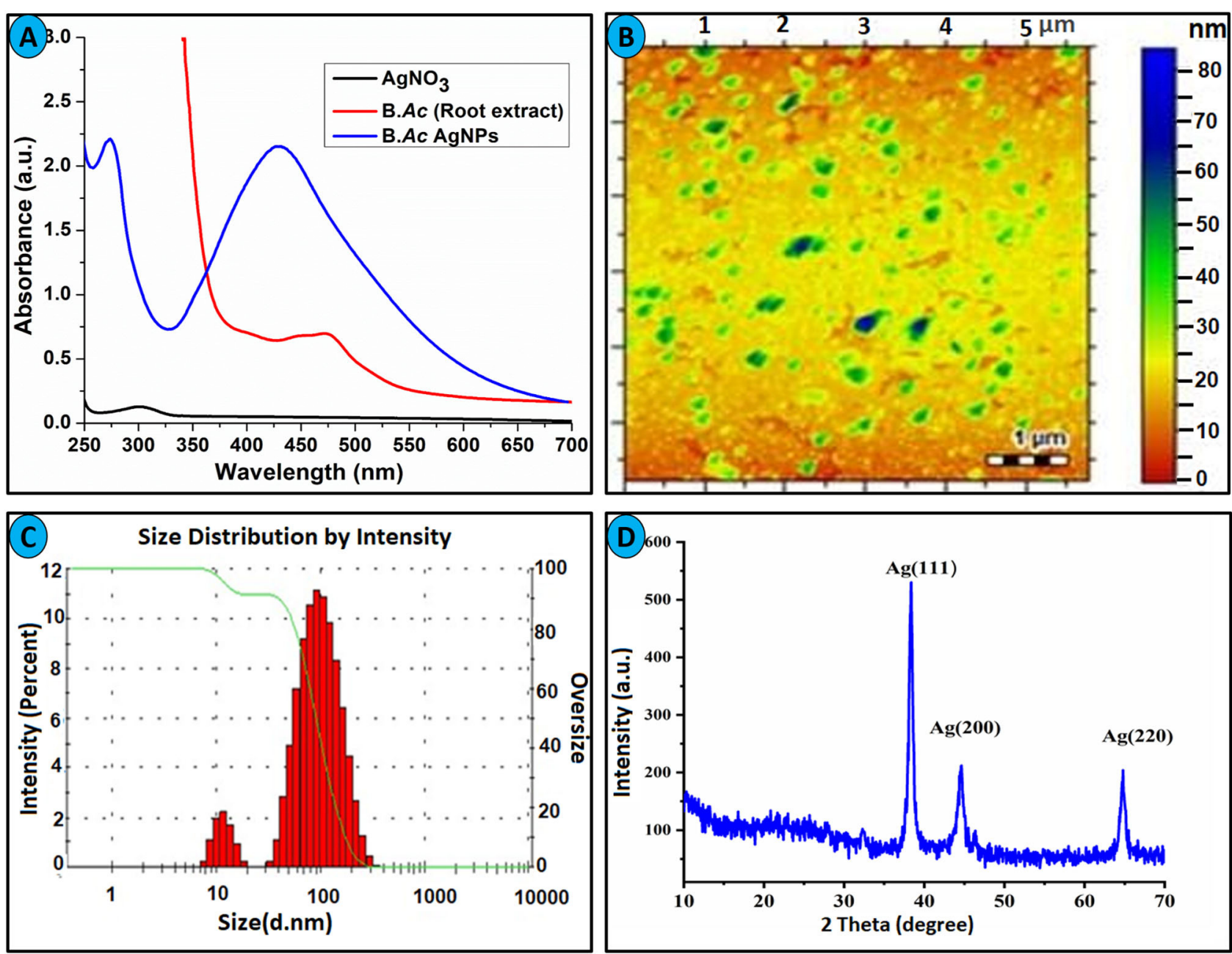

FIGURE 1 | (A) UV-visible spectra of Bistorta amplexicaulis root extract stabilized AgNPs. (B) AFM image of AgNPs. (C) Average size distribution by intensity. (D) XRD spectrum of AgNPs. 
hydroxyl groups present in plant extract are well-known reductants for $\mathrm{Ag}^{+}$in the synthesis of polydispersed AgNPs. Silver nanoparticle showed maximum absorption intensity at 5:1 of $\left(\mathrm{AgNO}_{3}\right.$ : Bistorta amplexicaulis $\left.\mathrm{v} / \mathrm{v}\right)$, while upon the increasing concentration of plant extract solution did not produce any significant change in the wavelength of nanoparticles while absorption intensity decreased slightly. The particle size of newly synthesized nanoparticles was determined using AFM and zeta sizer analysis. AFM investigation was employed to observe the surface morphology and an average particle size of the synthesized nanoparticle. AFM analysis showed that most of AgNPs are spherical with an average size between 50 and $60 \mathrm{~nm}$ (Figure 1B). The bigger particles in the AFM image can be described as the assembly of smaller NPs. The size of nanoparticles was also measured by Zetasizer analysis which demonstrated that nanoparticles have an average size of around $60 \mathrm{~nm}$ with a poly dispersive index value of 0.39 (Figure 1C).

Bistorta amplexicaulis stabilized nanoparticles were also characterized by XRD analysis to confirm the crystal nature of synthesized nanoparticles. The XRD pattern exhibited distinctive Bragg reflections, which may be cataloged on the basis of the specific crystalline structure of silver nanoparticles. The XRD graph showed three obvious peaks for AgNPs at $38.2^{\circ}$ (111), $44.3^{\circ}(200)$, and $64.5^{\circ}(220)$ as depicted in Figure 1D. These Bragg reflections resembled the crystalline planes of the facecentered cubic (fcc) crystal lattice of metallic silver. Thus, XRD analysis confirms the formation of AgNPs in the shape of the nanocrystal. The obtained XRD pattern of AgNPs is well-matched with the XRD results of plant extract stabilized nanoparticles reported in the literature (Umamaheswari et al., 2018; Santhosh et al., 2019). FT-IR spectroscopy was employed
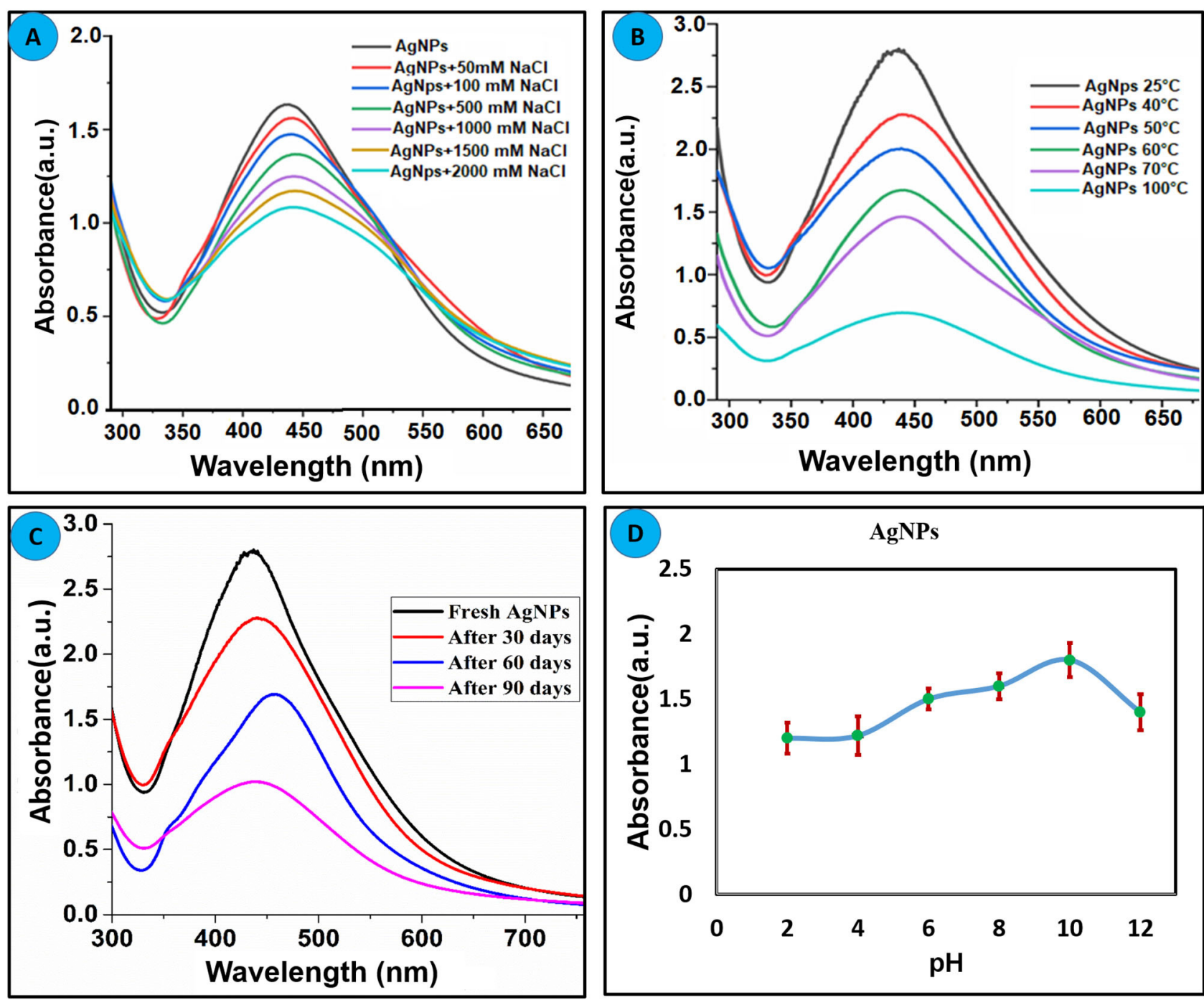

FIGURE 2 | Effect of the different parameters on the stability of green synthesized AgNPs (A) Effect of electrolyte concentration. (B) Thermal stability of AgNPs. (C) Effect of time on the stability of AgNPs. (D) Effect pH on the stability of AgNPs. 
to find out the nature of the functional group taking part in the stabilization of AgNPs. By matching the FT-IR spectrum of Bistorta amplexicaulis with AgNPs, biomolecules of different classes present in the root extract of Bistorta amplexicaulis, and their conjugation with silver is confirmed from 4,000 to $400 \mathrm{~cm}^{-1}$ range (Supplementary Figure 3). The FT-IR spectrum of the plant extract showed characteristic peaks of for $-\mathrm{OH},-\mathrm{CH},-\mathrm{C}=\mathrm{O}$, and $-\mathrm{NH}$ functional groups at 3,403 , $2,950,1,737$, and $1,622 \mathrm{~cm}^{-1}$, correspondingly. All the peaks presents indicate the presence of polyphenolic, carbohydrates, and protein-based function constituents in the plant extract. The sharp hydroxyl and $\mathrm{N}-\mathrm{H}$ (bend) peak at 3,403 and 1,622 $\mathrm{cm}^{-1}$ are disappeared in the FT-IR spectrum of AgNPs (Supplementary Figure 3) while the intensity of the carbonyl group $(-\mathrm{C}=\mathrm{O})$ decreased significantly. These changes in the FTIR spectrum of nanoparticles endorsed the major involvement of - $\mathrm{OH}$ and $-\mathrm{NH}$ containing biomolecules (present in root extract) in the stabilization of nanoparticles.

\section{Stability of Bistorta amplexicaulis Coated AgNPs}

Nanoparticles stability under different circumstances such as $\mathrm{pH}$, heat, and electrolyte concentration is considered as an important characteristic for the real application. To define the stability of synthesized silver nanoparticles, different experiments were carried out and results are summarized in Figure 2. Different concentration of $\mathrm{NaCl}(0.05-2 \mathrm{M})$ was mixed with AgNPs, and alteration in the absorbance was recorded as displayed in Figure 2A. It can be concluded that AgNPs are highly stable up to $1 \mathrm{M} \mathrm{NaCl}$ concentration. At a high concentration of $\mathrm{NaCl}$ $(2 \mathrm{M})$, the broadness in the absorption band and decline in the absorbance of nanoparticles is attributed to the aggregation effect of the chlorine ion (Bae et al., 2002). To explore the thermal stability of AgNPs, experiments were conducted at an elevated temperature. The nanoparticle solution was heated to the different temperatures, and change in absorption intensity was recorded as shown in Figure 2B. Bistorta amplexicaulis

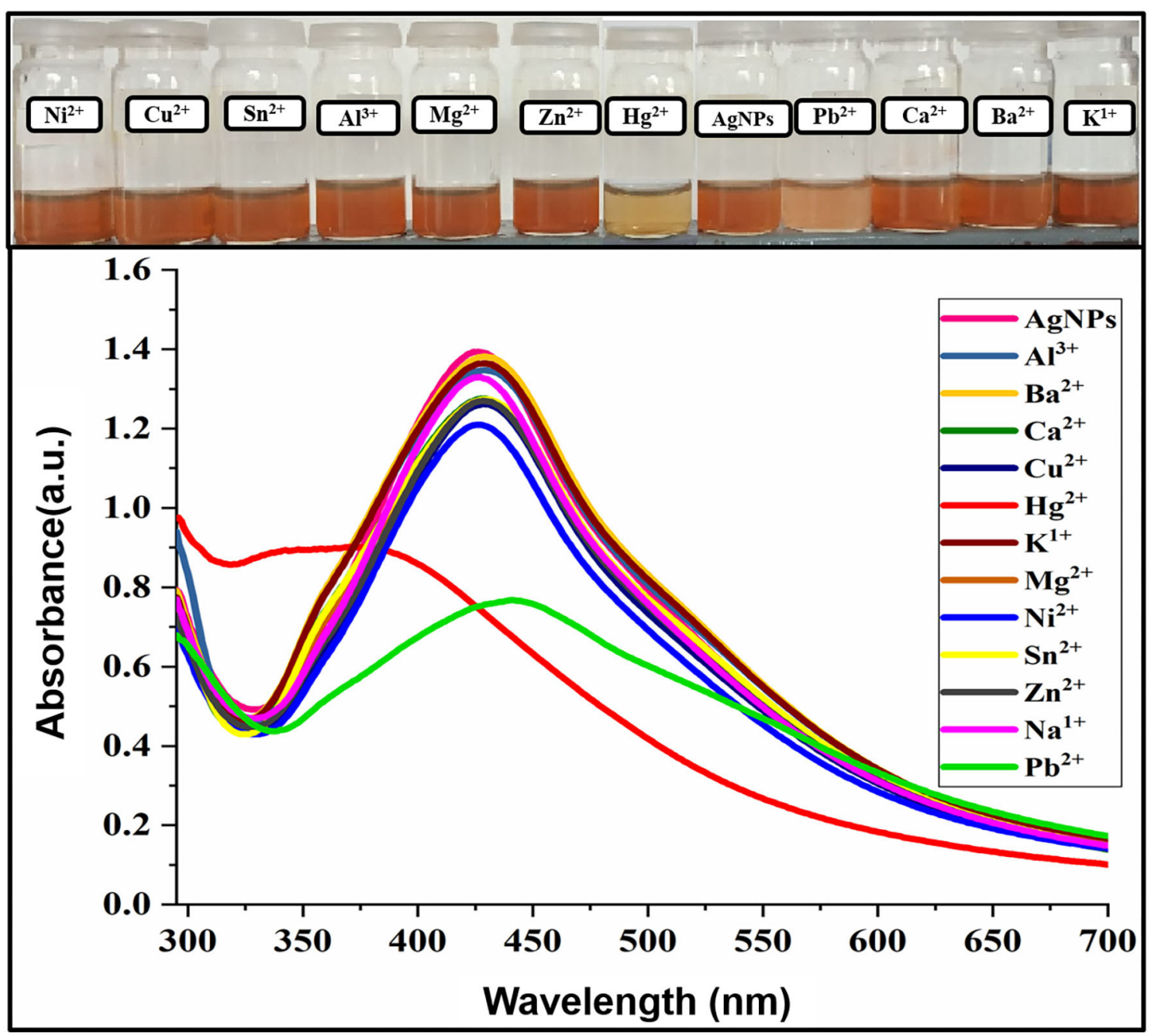

FIGURE 3 | Change in absorption intensity and the colorimetric response of AgNPs upon the addition of several metal ions. 


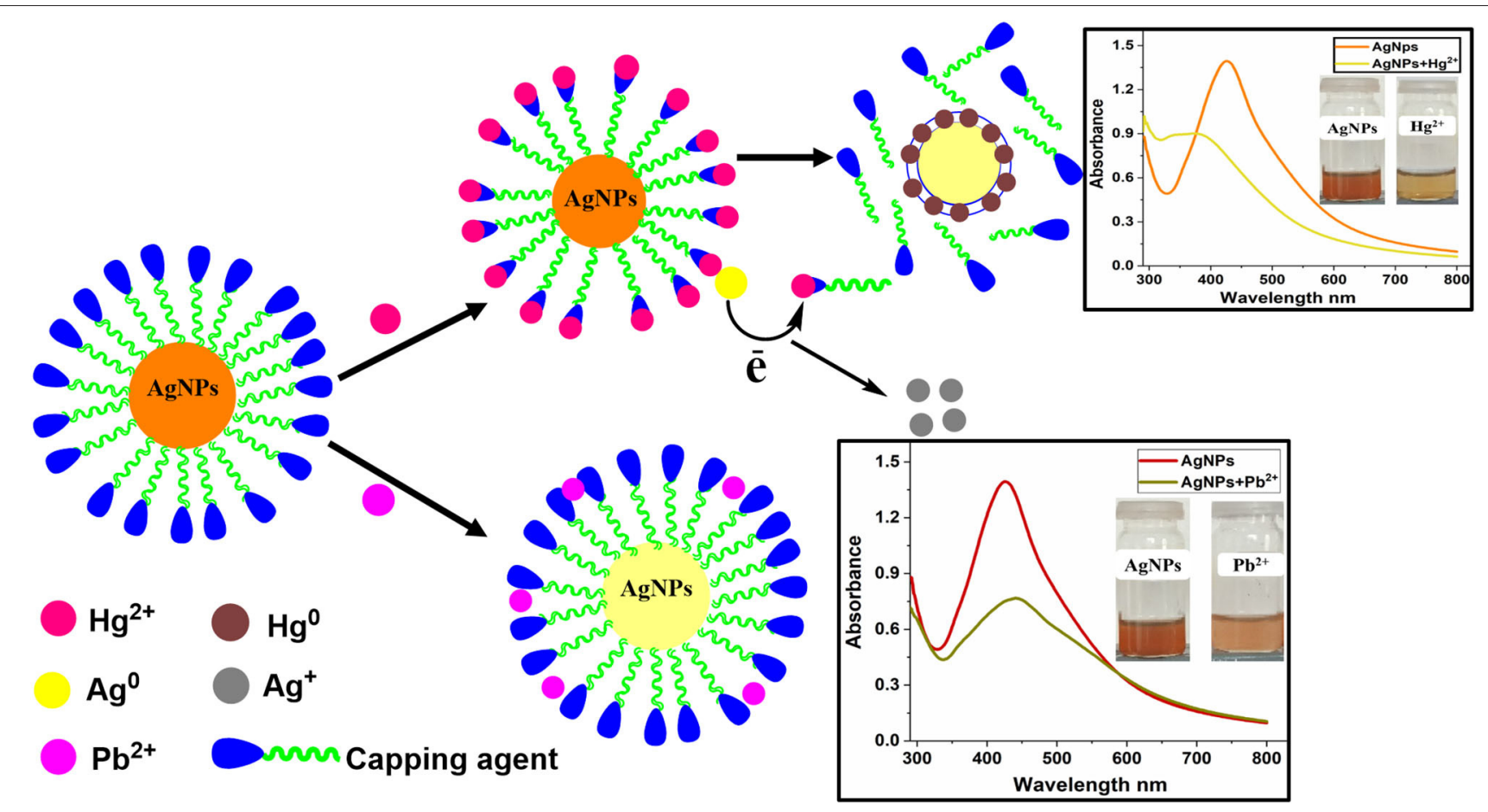

SCHEME 1 | Possible sensing mechanism for $\mathrm{Hg}^{2+}$ and $\mathrm{Pb}^{2+}$ using Bistorta amplexicaulis stabilized AgNPs.

coated AgNPs were stable up to $70^{\circ} \mathrm{C}$ whereas a significant decrease in the absorption intensity was observed at a higher temperature without any precipitation which attributed to the dominant electronic dephasing mechanism (Link et al., 1999). To estimate the effect of time on the stability of nanoparticles, change in the absorption intensity was recorded in a different time interval as depicted in Figure 2C. It can be concluded from the figure that nanoparticles are quite stable up to 60 days but after that stability decreased. The $\mathrm{pH}$ of the medium plays a critical role in the synthesis and stabilization of the biogenic synthesized nanoparticles. The main effect of the reaction $\mathrm{pH}$ is its stability to alter the electrical charges of biomolecules which might affect their capping and consequently the growth of the nanoparticles (Priya et al., 2016). The effect of $\mathrm{pH}$ on the stability of nanoparticles $\mathrm{pH}$-dependent was performed as depicted in Figure 2D, and it can be concluded that synthesized nanoparticles are stable over a wide range of $\mathrm{pH}(2-12)$. A slight decrease in the absorption intensity of nanoparticles was observed in high $\mathrm{pH}$ value which might be due to deprotonation of capping agents.

\section{Sensing Application of AgNPs Toward Metal Ions}

The photophysical potential of newly synthesized nanoparticle toward metal cations was studied via colorimetry and absorption spectroscopy. For the recognition study $1.0 \mathrm{~mL}$ of nanoparticles was mixed with $1.0 \mathrm{~mL}$ of various metals $(100 \mu \mathrm{M})$ at room temperature and changes in absorption intensity were recorded. The addition of $\mathrm{Hg}^{2+}$ and $\mathrm{Pb}^{2+}$ in AgNPs solution gives a colorimetric response within $5 \mathrm{~min}$ as the dark brown color of AgNPs change to light yellow upon the addition of $\mathrm{Hg}^{2+}$ and light brown in the case of $\mathrm{Pb}^{2+}$ revealing the binding of $\mathrm{Hg}^{2+}$ and $\mathrm{Pb}^{2+}$ with AgNPs as depicted in Figure 3. The absorption spectra showed the broadness and blue shift in the absorption band upon interaction with mercury $\mathrm{Hg}^{2+}$ and hypochromic shift in presence of lead $\mathrm{Pb}^{2+}$. All other metals, including $\mathrm{Cu}^{2+}$, $\mathrm{Zn}^{2+}, \mathrm{Mg}^{2+}, \mathrm{Ni}^{2+}, \mathrm{Na}^{+}, \mathrm{K}^{+}, \mathrm{Al}^{3+}, \mathrm{Ba}^{2+}, \mathrm{Ca}^{2+}$, and $\mathrm{Sn}^{2+}$ did not make any alteration in the color and absorption spectrum of the nanoparticles. $\mathrm{Hg}^{2+}$ and $\mathrm{Pb}^{2+}$ were the only two metals that caused the remarkable change which can be distinguished by the naked eye and absorption band of AgNPs. These results demonstrated good selectivity for these metal ions over a wide range of other tested metals, thus AgNPs have specific binding sites for mercury $\left(\mathrm{Hg}^{2+}\right)$ and lead $\left(\mathrm{Pb}^{2+}\right)$. The presence of organic functional groups $\left(-\mathrm{COOH},-\mathrm{NH}_{2},-\mathrm{OH}\right.$, etc.) in the stabilizing agent facilitates the binding of mercury on to the surface of AgNPs (Farhadi et al., 2012; Kamali et al., 2016).

The possible mechanism for the selective recognition of $\mathrm{Hg}^{2+}$ can be explained based on redox reaction taking place at the surface of the AgNPs, due to the differences in the standard potential of $0.8 \mathrm{~V}\left(\mathrm{Ag}^{+} / \mathrm{Ag}\right)$ and $0.85 \mathrm{~V}\left(\mathrm{Hg}^{2+/} \mathrm{Hg}\right)$. Upon addition of $\mathrm{Hg}^{+2}$ to the colloidal AgNPs suspension, the presence of organic capping agents on the surface of AgNPs stimulates electrostatic-ionic attractions between the NPS and $\mathrm{Hg}^{2+}$ (Scheme 1). The added mercury reacts with the $\mathrm{Ag}^{0}$ core by redox reaction and displaces the capping agents present on the surface of the AgNPs. Flavonoids, carbohydrates, amino acids, and their derivatives are present in plant extracts and are known 
to form complexes with heavy metal cations (Sumi et al., 2017). As a result of these redox reactions taking place between $\mathrm{Ag}^{0}$ and mercury, $\mathrm{Hg}^{2+}$ gets reduced to $\mathrm{Hg}^{0}$ on the nanoparticle surface and $\mathrm{Ag}^{0}$ oxidized to $\mathrm{Ag}^{+}$. As the AgNPs are converted to $\mathrm{Ag}^{+}$ ions by added mercury, the colloidal solution becomes colorless. The result demonstrates that the accessible $\mathrm{Ag}^{0}$ in the colloidal suspension has been completely oxidized by the added quantity of mercury.

\section{Effect of Mercury $\left(\mathrm{Hg}^{2+}\right)$ and Lead $\left(\mathrm{Pb}^{2+}\right)$ Concentration}

Sensitivity toward a particular analyte is a vital parameter of a sensory system. Maintaining the concentration of nanoparticles constant, the concentration of $\mathrm{Hg}^{2+}(1-70 \mu \mathrm{M})$ and $\mathrm{Pb}^{2+}(1-$ $90 \mu \mathrm{M})$ was varied and the effect of different concentrations of selected ions on the absorption intensity of AgNPs was recorded as shown in Figures 4A,B. A linear relationship between concentration and absorption intensity was found for both $\mathrm{Hg}^{2+}$ and $\mathrm{Pb}^{2+}$ with a correlation factor of $R^{2}$ $=0.9956, R^{2}=0.9959$ for the range of $1-70 \mu \mathrm{M}$, and $1-$ $90 \mu \mathrm{M}$, respectively. The limit of detection of $\mathrm{Hg}^{2+}$ and $\mathrm{Pb}^{2+}$ was calculated using a slope of the straight-line equation and standard deviation of the blank using the following formula $\mathrm{LOD}=\mathrm{F} \times \mathrm{SD} / \mathrm{b}$. The lower limit of detection for $\mathrm{Hg}^{2+}$ and
$\mathrm{Pb}^{2+}$ was calculated to be $8.0 \times 10^{-7} \mathrm{M}$ and $2.0 \times 10^{-7}$ $\mathrm{M}$ correspondingly. The comparison of the present study with reported methods for the recognition of $\mathrm{Hg}^{2+}$ and $\mathrm{Pb}^{2+}$ is shown in Tables 1, 2, respectively. As can be seen from the tables that are lower limit of detection for $\mathrm{Hg}^{2+}$ and $\mathrm{Pb}^{2+}$ is comparable with recently reported methods. The comparison shows that biogenic synthesized nanoparticle is a very efficient, cost-effective, and more importantly environmental-friendly sensor for the detection and quantification of the micromolar concentration of $\mathrm{Hg}^{2+}$ and $\mathrm{Pb}^{2+}$ ions.

\section{Interfering Study}

Detection of the targeted analyte with high selectivity in the presence of other similar analytes is an essential property of a sensor when used for analytical applications. To find out the selectivity of AgNPs toward selected metal ions, competitive experiments were performed in the existence of other metal ions. Several metal ions $(100 \mu \mathrm{M})$ were treated with AgNPs in the presence of $\mathrm{Hg}^{2+}(100 \mu \mathrm{M})$ and $\mathrm{Pb}^{2+}(100 \mu \mathrm{M})$ under similar experimental conditions, and variation in the absorbance was recorded. It can be concluded from competitive experiments that no substantial change in the absorbance was observed with the addition of interfering metals ions, and the absorption intensity was nearly parallel to that caused by $\mathrm{Hg}^{2+}$ and $\mathrm{Pb}^{2+}$ alone as
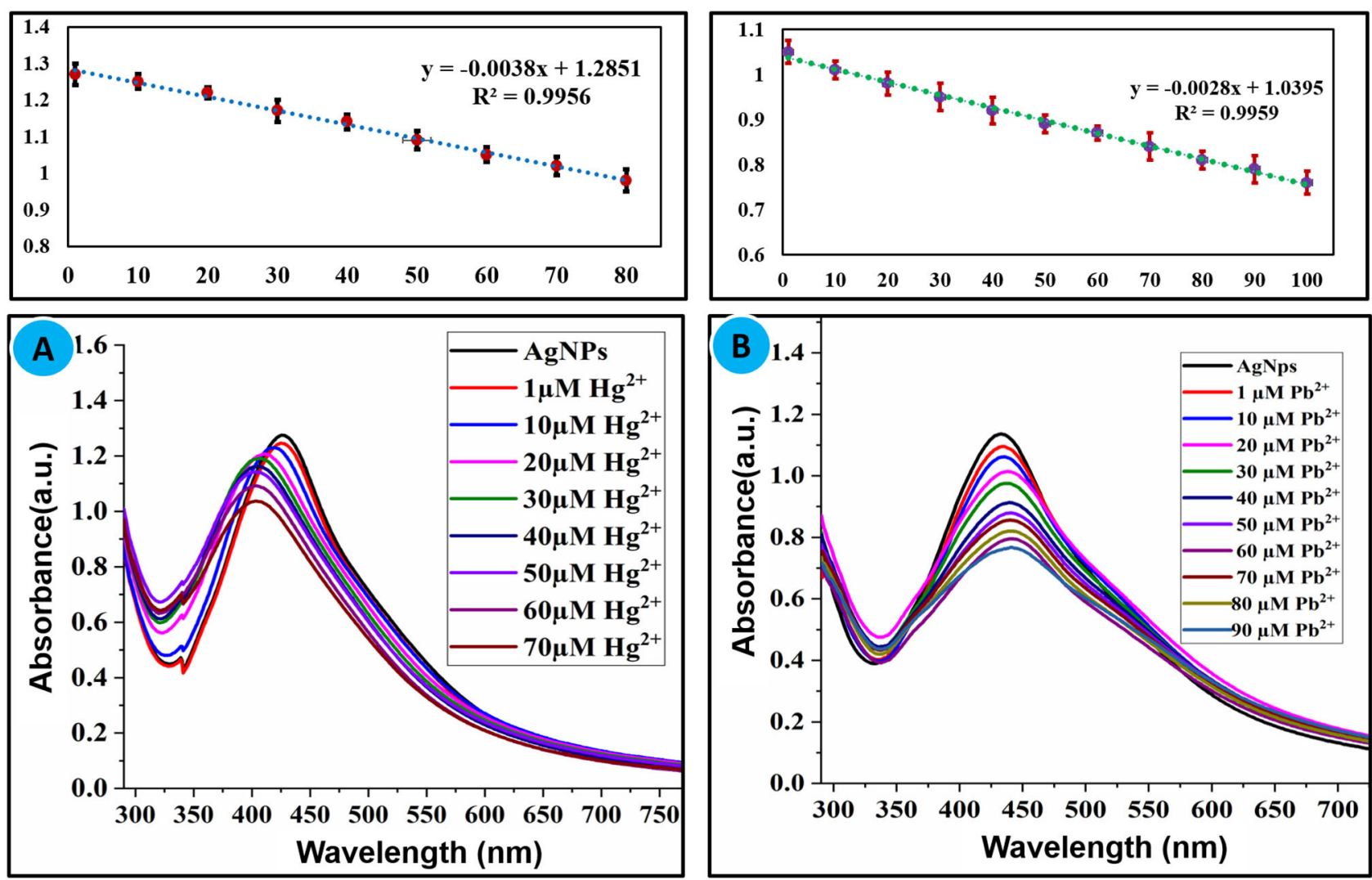

FIGURE 4 | (A) Effect of concentration of $\mathrm{Hg}^{2+}(1-70 \mu \mathrm{M})$ and (B) $\mathrm{Pb}^{2+}(1-90 \mu \mathrm{M})$ on the absorption intensity of AgNPs. 
TABLE 1 | Comparison of current study with reported methods for the detection of $\mathrm{Hg}^{2+}$.

\begin{tabular}{|c|c|c|c|c|}
\hline Responsive technique & Sensor & $\begin{array}{l}\text { Limit of } \\
\text { detection } \\
\text { (M) }\end{array}$ & $\begin{array}{l}\text { Synthetic } \\
\text { approach }\end{array}$ & References \\
\hline Colorimetry & Melamine stabilized AgNPs & $2 \times 10^{-6}$ & Chemical method & Kailasa et al., 2018 \\
\hline Colorimetry & PEG-Iuteolin stabilized AgNPs & $2 \times 10^{-6}$ & Chemical method & Qing et al., 2018 \\
\hline $\begin{array}{l}\text { Colorimetric and UV-visible } \\
\text { spectroscopy }\end{array}$ & $\begin{array}{l}\text { Phenylenediamine functionalized silver } \\
\text { nanoparticles (AgNPs) }\end{array}$ & $8.0 \times 10^{-7}$ & Chemical method & Bothra et al., 2013 \\
\hline Cyclic voltammetry & Arbutus andrachne Stabilized AgNPs & $8.43 \times 10^{-6}$ & Green chemistry & Eksin et al., 2019 \\
\hline $\begin{array}{l}\text { Colorimetric and UV-visible } \\
\text { spectroscopy }\end{array}$ & $\begin{array}{l}\text { Syzygium aqueum extract stabilized } \\
\text { AgNPs }\end{array}$ & $8.7 \times 10^{-7}$ & Green chemistry & Firdaus et al., 2017 \\
\hline $\begin{array}{l}\text { Colorimetric and } \\
\text { spectrophotometric }\end{array}$ & Bistorta amplexicaulis stabilized AgNPs & $8.0 \times 10^{-7}$ & Green chemistry & Current study \\
\hline
\end{tabular}

TABLE 2 | Comparison of the current study with reported methods for detection of $\mathrm{Pb}^{2+}$.

\begin{tabular}{|c|c|c|c|c|}
\hline Responsive technique & Sensor & $\begin{array}{l}\text { Limit of } \\
\text { detection (M) }\end{array}$ & $\begin{array}{l}\text { Synthetic } \\
\text { approach }\end{array}$ & References \\
\hline UV-Visible and Colorimetry & Gold nanoparticles & $5.0 \times 10^{-7}$ & Chemical method & Wei et al., 2008 \\
\hline UV-Visible and Colorimetry & Schiff base sensor & $5.4 \times 10^{-6}$ & Chemical method & Wang et al., 2018 \\
\hline UV-visible and fluorescence & Quinoline-coumarin based sensor & $5.0 \times 10^{-7}$ & Chemical method & Meng et al., 2018 \\
\hline Voltammetry & Bismuth oxycarbide/nafion electrode & $3.5 \times 10^{-6}$ & Chemical method & Zhang et al., 2020 \\
\hline $\begin{array}{l}\text { Colorimetric and UV-visible } \\
\text { spectroscopy }\end{array}$ & Bistorta amplexicaulis stabilized AgNPs & $2.0 \times 10^{-7}$ & Green approach & Current study \\
\hline
\end{tabular}

shown in Figures 5A,B. This undoubtedly suggests that AgNPs are highly selective in the sensing of $\mathrm{Hg}^{2+}$ and $\mathrm{Pb}^{2+}$ without any interference from other tested metal ions.

\section{Effect of $\mathrm{pH}$ and Binding Stoichiometry}

The $\mathrm{pH}$ value of the medium had a remarkable effect on the stability and sensing applications of nanoparticles. To optimize the effect of $\mathrm{pH}$ on the sensing potential of AgNPs toward $\mathrm{Hg}^{2+}$ and $\mathrm{Pb}^{2+}$, experiments were carried out under different $\mathrm{pH}$ from 2 to 12 . An aqueous solution of $\mathrm{NaOH}$ $(0.1 \mathrm{M})$ and $\mathrm{HCl}(0.1 \mathrm{M})$ was used to control the $\mathrm{pH}$ value. Absorption spectra were recorded at room temperature and the graph was plotted between absorbance vs. $\mathrm{pH}$ as shown in Figures 6A,B. The result revealed that AgNPs can be employed for the recognition of $\mathrm{Hg}^{2+}$ and $\mathrm{Pb}^{2+}$ over a wide range of $\mathrm{pH}$. The binding stoichiometry of the AgNPs-mercury complex and AgNPs-lead complex was monitored by the job's plot method. Keeping the total concentration constant mole fraction value of AgNPs and selected metal ions were varied from 0.1 to 0.9 . Change in the absorbance was recorded, and the graph was plotted between absorbance and mole fraction of $\mathrm{Hg}^{2+}$ and $\mathrm{Pb}^{2+}$ ions. It can be seen from Figures 6C,D that maximum reduction in the absorption intensity was observed at a mole fraction value of around 0.6. These results suggested 1:1 binding stoichiometry between AgNPs and selected metal ions.

\section{Detection of $\mathrm{Hg}^{2+}$ and $\mathrm{Pb}^{2+}$ in Tap Water}

The practical applicability of AgNPs detection of selected metal ions was carried out in the tap water sample. Tap water samples were collected from Bagh Azad Kashmir and spiked with a known concentration $(100 \mu \mathrm{M})$ of $\mathrm{Hg}^{2+}$ and $\mathrm{Pb}^{2+}$ ions. The freshly prepared solution of $\mathrm{Pb}^{2+}$ and $\mathrm{Hg}^{2+}$ were mixed with AgNPs solution at room temperature and change in absorbance was noted as presented in Figure 7. Tap water analysis revealed that a component present in tap water didn't interfere in the detection of $\mathrm{Hg}^{2+}$ and $\mathrm{Pb}^{2+}$. Hence green synthesized AgNPs can be employed for the selective detection of $\mathrm{Hg}^{2+}$ and $\mathrm{Pb}^{2+}$ ion in the environmental samples without any interference from other similar metal ions.

\section{Evaluation of the Catalytic Activity of AgNPs}

Newly synthesized AgNPs were explored for their catalytic activity toward the degradation of methyl orange dye. Methyl orange is a polar dye highly soluble in water. It is used extensively as a dye in the fabric production as well as the $\mathrm{pH}$ indicator. The color of methyl orange is orange-red due to the presence of the azo group which absorbs visible radiations resulting in a clear peak at $464 \mathrm{~nm}$ in a UV-visible spectrum. The degradation of methyl orange can be examined spectrophotometrically. Methyl orange solution was mixed with solid AgNPs $(2 \mathrm{mg} / 5 \mathrm{~mL})$ and the resulted solution was stirred at $25^{\circ} \mathrm{C}$ for $15 \mathrm{~min}$, and dye color change and absorption intensity were monitored. Degradation 

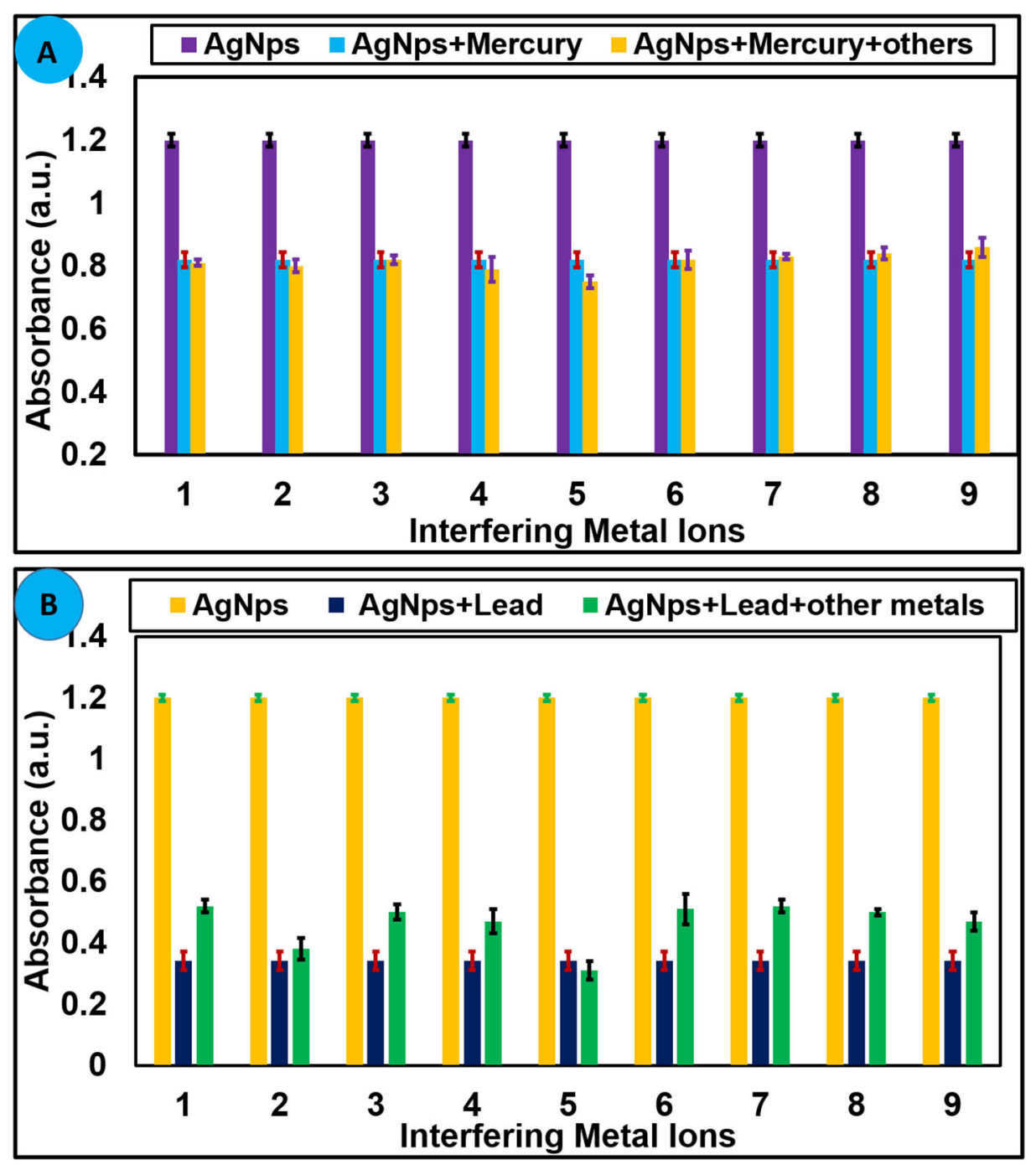

FIGURE 5 | (A) Selectivity of AgNPs toward $\mathrm{Hg}^{2+}(70 \mu \mathrm{M})$ at $427 \mathrm{~nm}$ and (B) toward $\mathrm{Pb}^{2+}(100 \mu \mathrm{M})$ in presence of several metal cations. $1=\mathrm{Ni}^{2+}, 2=\mathrm{Zn}^{2+}, 3=$ $\mathrm{Mg}^{2+}, 4=\mathrm{Ca}^{2+}, 5=\mathrm{Sn}^{2+}, 6=\mathrm{Cr}^{3+}, 7=\mathrm{K}^{+}, 8=\mathrm{Na}^{+}, 9=\mathrm{Al}^{3+}$, and $10=\mathrm{Cu}^{2+}$.

reaction proceeds immediately upon the addition of AgNPs that can be visualized by the fading orange color of the dye with a reduction in absorption intensity of the band at $464 \mathrm{~nm}$ as publicized in Figure 8A. The dark orange solution of methyl orange was being changed to a colorless solution within $15 \mathrm{~min}$, and a significant decrease in the absorption intensity was also recorded. These results proposed that AgNPs cleaved the $\mathrm{N}=\mathrm{N}$ - functional group of methyl orange which subsequently decolorizes the target solution (Naseem et al., 2019; Raj et al., 2020). The $\mathrm{BH}_{4}^{-1}$ and methyl orange adsorb on the surface of nanoparticles in aqueous solution. The hydrogen from $\mathrm{BH}_{4}^{-1}$ acting as a source of hydrogen can absorb on the surface of AgNPs and attack on azo function group of methyl orange. The electron carrying NPS triggers the catalytic surface and activates azo bond of methyl orange which results as breakage of $-\mathrm{N}=\mathrm{N}$ bonds due to the acceptance of electron via catalyst, further the hydrogen released from $\mathrm{BH}_{4}^{-1}$ and dyes get reduced on the surface of nanoparticles.

AgNPs with the properties of low volume to the high surface area can increase the rate of reduction for dye degradation. To optimize the amount of AgNPs catalyst, different amount of nanoparticles $(1-3 \mathrm{mg})$ is treated with a constant concentration of methyl orange under the same conditions, an amendment in the absorption intensity was noted as depicted in Figure 8B. It showed the rate of decay of dye increase with the increase of the amount of the nano-catalyst (AgNPs) due to the high availability of the catalyst (high surface area) (Bogireddy et al., 2016). The reaction time has a foremost effect on the degradation process. The reaction was performed with a constant concentration of methyl orange $(0.1 \mathrm{mM})$ at $25^{\circ} \mathrm{C}$, and nanocatalyst $(1 \mathrm{mg})$ reaction time is varied at $0-15 \mathrm{~min}$. The change in the absorbance of methyl orange was recorded as shown in 

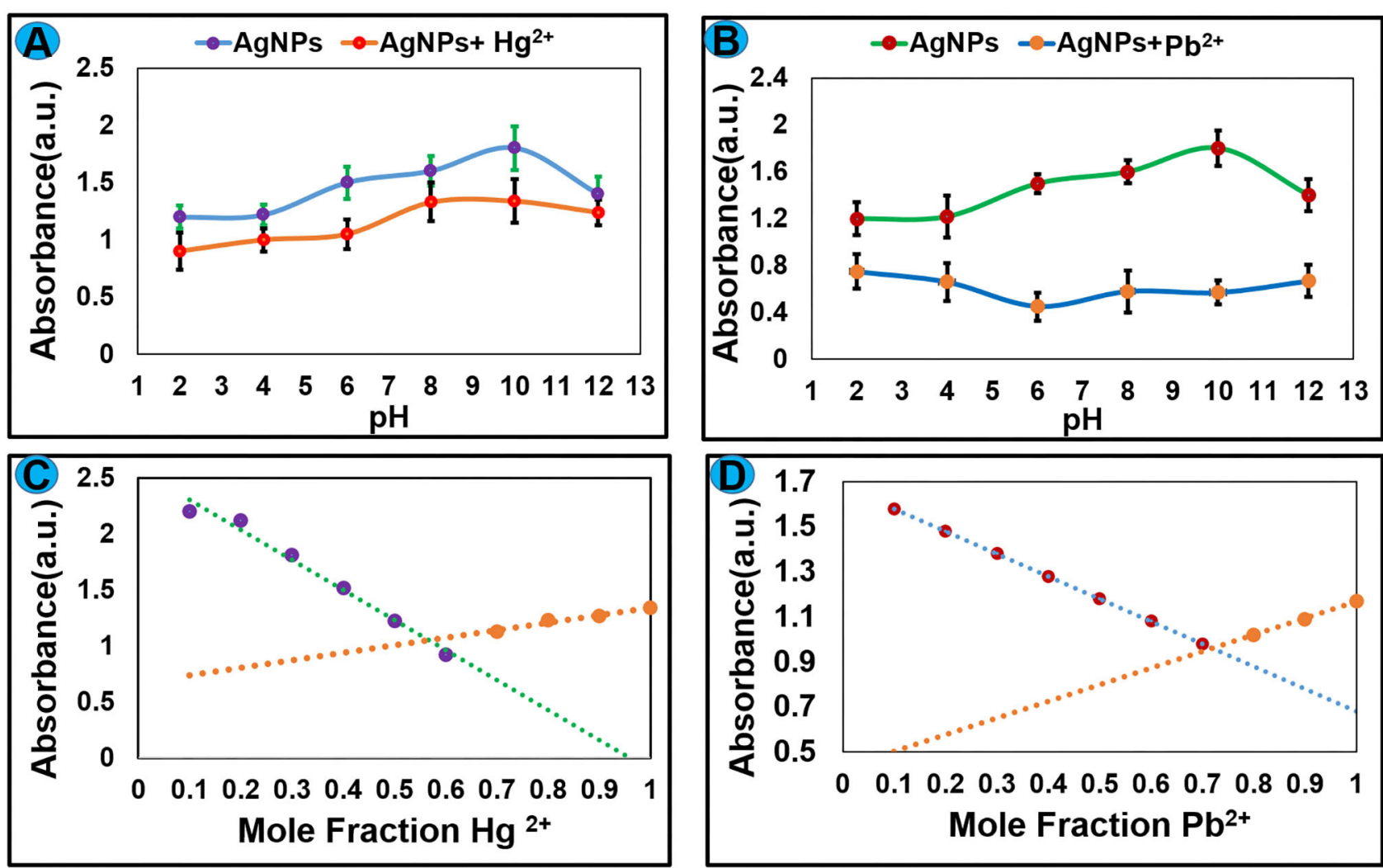

FIGURE 6 | The effect of $\mathrm{pH}$ on the complex formation between AgNPs and (A) $\mathrm{Hg}^{2+}$ and (B) Pb ${ }^{2+}$. Job's plot for binding stoichiometry between AgNPs and selected metal ions (C) $\mathrm{Hg}^{2+}$ and (D) $\mathrm{Pb}^{2+}$.

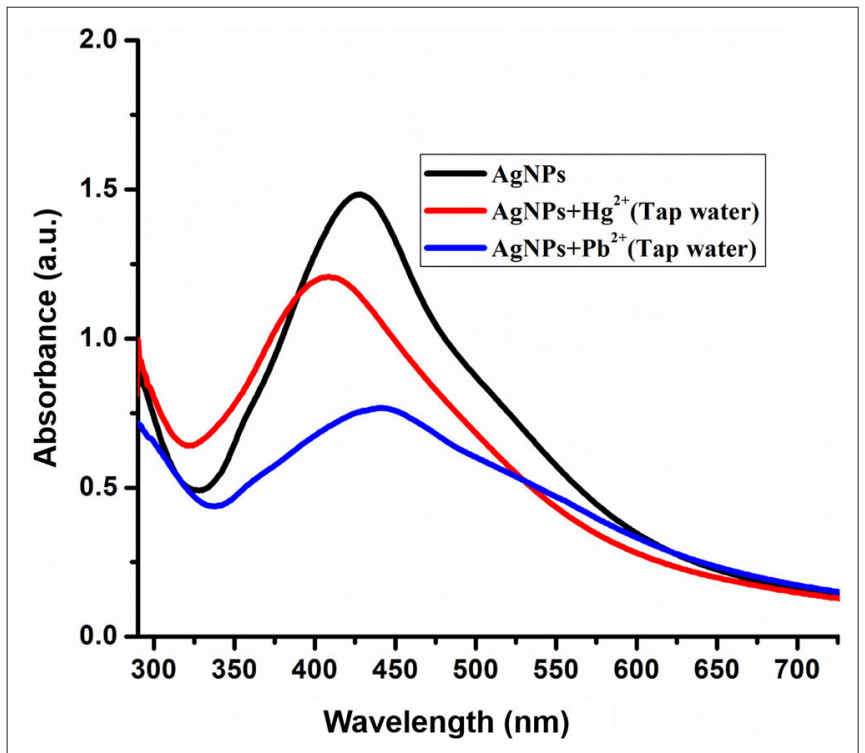

FIGURE 7 | Spectra shows the detection of $\mathrm{Hg}^{2+}(100 \mu \mathrm{M})$ and $\mathrm{Pb}^{2+}$ $(100 \mu \mathrm{M})$ in laboratory tap water.

Figure 8C. The obtained results showed that the rate of methyl orange degradation is directly proportional to reaction time, and the equilibrium reaction rate is attained at optimal contact time. The change in the absorption intensity of methyl orange is plotted vs. reaction time (Figure 8D), which gives a straight line equation with $R^{2}=0.9927$ and rate value of $0.0284 \mathrm{~min}^{-1}$. Table 3 lists various classic methods reported in the literature for the degradation of methyl orange concerning reaction time and catalyst dose. The results from the current study are also listed. Most of the reported methods are based on a complex chemical synthetic approach. In contrast, the current study is based on a simple, cheap, and more environment-friendly green synthesized AgNPs based nano-catalyst for efficient degradation of methyl orange.

\section{CONCLUSIONS}

In this research work, we have developed highly stable green synthesized silver nanoparticles (AgNPs) by a simple, cheap, and ecological friendly biogenic route. The root extract of Bistorta amplexicaulis plant was acted as a reducing and capping agent for the stabilization of AgNPs. Aqueous extract of Bistorta amplexicaulis containing several biomolecules (such as carbohydrates, amino acid, phenol, and triterpenes) are effective for the stabilization of AgNPs. Newly synthesized AgNPs were characterized by several spectroscopic techniques. $\mathrm{Hg}^{2+}$ and $\mathrm{Pb}^{2+}$ ion produce a substantial effect on the absorption band 


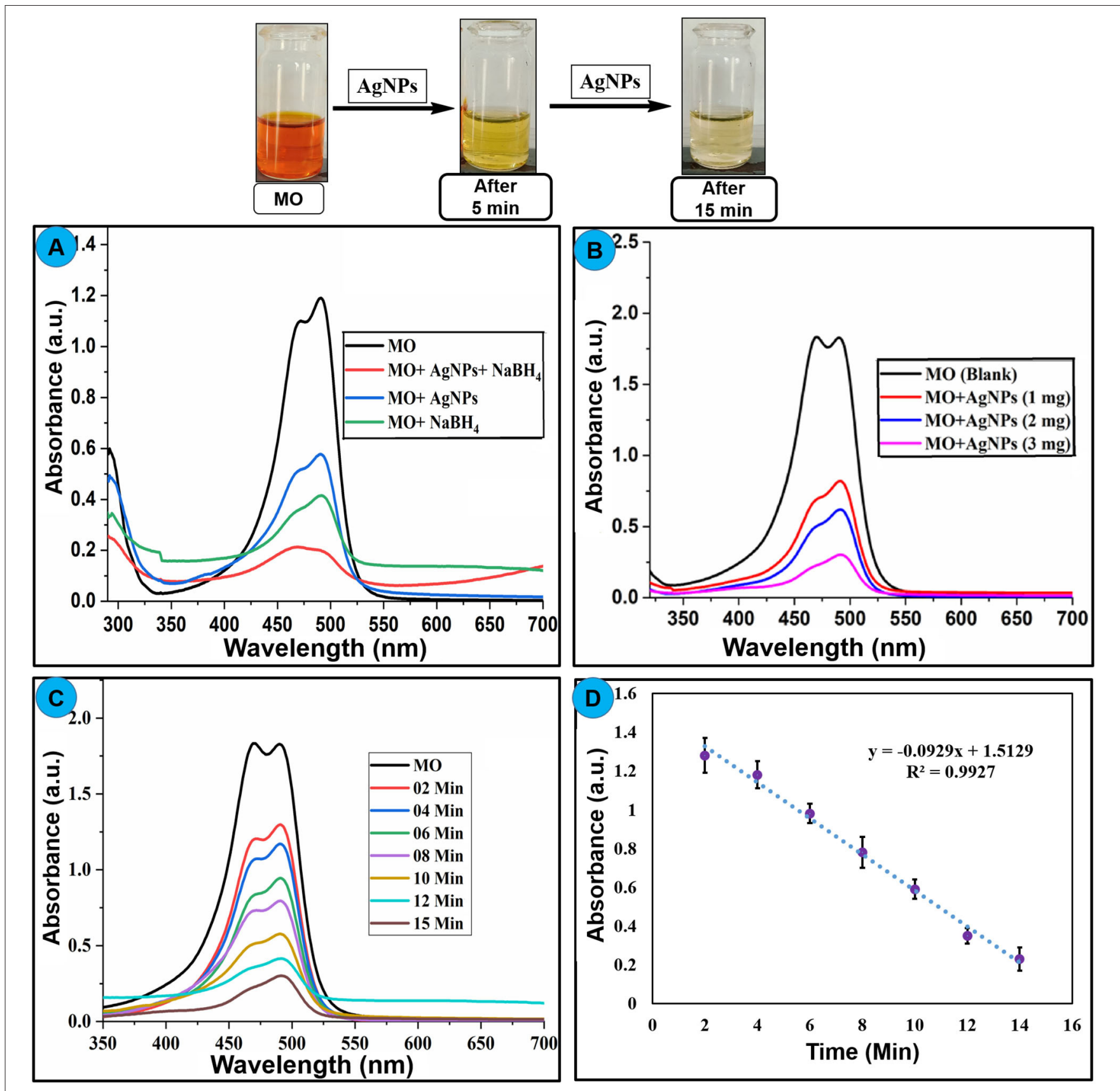

FIGURE 8 | (A) Change in UV-Visible absorption spectra of methyl orange upon treatment with $\mathrm{AgNPs}, \mathrm{NaBH}_{4}, \mathrm{and} \mathrm{AgNPs}_{\mathrm{N}} \mathrm{NaBH}_{4}$, (B) effect of different amount of nanoparticle on the degradation of dye, (C) effect of reaction time on the degradation of methyl orange using AgNPs at 2-min intervals, (D) change in absorption intensity of methyl orange at $464 \mathrm{~nm}$ at different time interval, upon addition of AgNPs catalyst.

of AgNPs accompanied by naked eye detectable color change. The change in color of AgNPs from dark brown to light yellow for $\mathrm{Hg}^{2+}$ and dark brown to light brown for $\mathrm{Pb}^{2+}$ due to complexation and aggregation of AgNPs in the solution. The limit of detection of $\mathrm{Hg}^{2+}$ and $\mathrm{Pb}^{2+}$ is in the micromolar range, comparing with the reported protocols. The designed sensing approach is highly selective for $\mathrm{Hg}^{2+}$ and $\mathrm{Pb}^{2+}$ as no interference is observed in the competitive experiments. Further, synthesized nanoparticles were admirably used for the recognition of the above-mentioned analytes in tap water samples without any pre-treatment process. Further AgNPs were found to be an effective catalyst for the degradation of methyl orange dye. This innovative protocol has numerous advantages over the published colorimetric sensors due to 
TABLE 3 | Comparison of the current method for degradation of methyl orange with reported methods.

\begin{tabular}{llllll}
\hline Entry & Catalyst & $\begin{array}{l}\text { Catalyst dose } \\
(\mathbf{m g})\end{array}$ & Time (min) & Degradation (\%) & References \\
\hline 1 & MnFe $_{2} \mathrm{O}_{4}$ & 2.5 & 90 & 100 & Nguyen et al., 2011 \\
2 & Iron nanoclusters & 1.25 & 360 & 95 & Ebrahiminezhad et al., 2018 \\
3 & Co doped ZnO NPs & 0.5 & 90 & 100 & Ahmad, 2019 \\
4 & NiO NPs & 5.0 & 05 & 95 & Barzinjy et al., 2020 \\
5 & ZnO NPs & 3.0 & 100 & 81 & Gawade et al., 2017 \\
6 & AgNPs/Acacia nilotica & 5.0 & 06 & 95 & Shah et al., 2020 \\
7 & AgNPs/Bistorta amplexicaulis & 2.0 & 15 & 98 & Current work \\
\hline
\end{tabular}

its simplicity, high selectivity, cost-effectiveness, and more importantly environmental friendliness. Thus, obtained sensing and catalytic potential of AgNPs suggest the use of Bistorta amplexicaulis stabilized nanoparticle for detection of heavy metal ions and degradation of methyl orange.

\section{DATA AVAILABILITY STATEMENT}

All datasets generated for this study are included in the article/Supplementary Material.

\section{AUTHOR CONTRIBUTIONS}

FA conceived the experiments and drafted the manuscript. FA and HK conducted all the experiments. HX helped to discuss the

\section{REFERENCES}

Ahmad, I. (2019). Inexpensive and quick photocatalytic activity of rare earth (Er, $\mathrm{Yb})$ co-doped $\mathrm{ZnO}$ nanoparticles for degradation of methyl orange dye. Sep. Purif. Technol. 227:115726. doi: 10.1016/j.seppur.2019.115726

Annadhasan, M., Muthukumarasamyvel, T., Sankar Babu, V. R., and Rajendiran, N. (2014). Green synthesized silver and gold nanoparticles for colorimetric detection of $\mathrm{Hg}^{2+}, \mathrm{Pb}^{2+}$, and $\mathrm{Mn}^{2+}$ in aqueous medium. ACS Sustain. Chem. Eng. 2, 887-896. doi: 10.1021/sc400500z

Bae, C. H., Nam, S. H., and Park, S. M. (2002). Formation of silver nanoparticles by laser ablation of a silver target in $\mathrm{NaCl}$ solution. Appl. Surf. Sci. 197, 628-634. doi: 10.1016/S0169-4332(02)00430-0

Barzinjy, A. A., Hamad, S. M., Aydin, S., Ahmed, M. H., and Hussain, F. H. S. (2020). Green and eco-friendly synthesis of nickel oxide nanoparticles and its photocatalytic activity for methyl orange degradation. J. Mater. Sci. Mater. Electr. 31, 11303-11316. doi: 10.1007/s10854-020-03679-y

Bogireddy, N. K. R., Kumar, H. A. K., and Mandal, B. K. (2016). Biofabricated silver nanoparticles as green catalyst in the degradation of different textile dyes. J. Environ. Chem. Eng. 4, 56-64. doi: 10.1016/j.jece.2015.11.004

Bolisetty, S., Peydayesh, M., and Mezzenga, R. (2019). Sustainable technologies for water purification from heavy metals: review and analysis. Chem. Soc. Rev. 48, 463-487. doi: 10.1039/C8CS00493E

Bothra, S., Solanki, J. N., and Sahoo, S. K. (2013). Functionalized silver nanoparticles as chemosensor for $\mathrm{pH}, \mathrm{Hg}^{2+}$ and $\mathrm{Fe}^{3+}$ in aqueous medium. Sens Actuat B Chem. 188, 937-943. doi: 10.1016/j.snb.2013.07.111

Chang, K.-C., Su, I.-H., Lee, G.-H., and Chung, W.-S. (2007). Triazole-and azocoupled calix[4]arene as a highly sensitive chromogenic sensor for $\mathrm{Ca}^{2+}$ and $\mathrm{Pb}^{2+}$ ions. Tetrahedron Lett. 48, 7274-7278. doi: 10.1016/j.tetlet.2007.08.045

Chiang, C.-K., Huang, C. -C., Liu, C.-W., and Chang, H.-T. (2008). Oligonucleotide-based fluorescence probe for sensitive and selective results. All authors contributed to the article and approved the submitted version.

\section{ACKNOWLEDGMENTS}

We thank the Science and Technology Innovation Commission of Shenzhen (JCYJ20170818143131729) and (KQJSCX20180328095517269) for the research grant.

\section{SUPPLEMENTARY MATERIAL}

The Supplementary Material for this article can be found online at: https://www.frontiersin.org/articles/10.3389/fchem. 2020.591958/full\#supplementary-material detection of mercury(II) in aqueous solution. Anal. Chem. 80, 3716-3721. doi: 10.1021/ac800142k

Choudhary, M. K., Garg, S., Kaur, A., Kataria, J., and Sharma, S. (2020). Green biomimetic silver nanoparticles as invigorated colorimetric probe for $\mathrm{Hg}^{2+}$ ions: a ner approach towards recognition of heavy metal ions in aqueous media. Mater. Chem. Phys. 240:122164. doi: 10.1016/j.matchemphys.2019.122164

Dhand, V., Soumya, L., Bharadwaj, S., Chakra, S., Bhatt, D., and Sreedhar, B. (2016). Green synthesis of silver nanoparticles using Coffea arabica seed extract and its antibacterial activity. Mater. Sci. Eng. C 58, 36-43. doi: 10.1016/j.msec.2015.08.018

Dooyema, C. A., Neri, A., Lo, Y.-C., Durant, J., Dargan, P. I., Swarthout, T., et al. (2012). Outbreak of fatal childhood lead poisoning related to artisanal gold mining in northwestern Nigeria, 2010. Environ. Health Perspect. 120, 601-607. doi: 10.1289/ehp.1103965

Durand, M.-J., Hua, A., Jouanneau, S., Cregut, M., and Thouand, G. (2015). "Detection of metal and organometallic compounds with bioluminescent bacterial bioassays," in Bioluminescence: Fundamentals and Applications in Biotechnology, Vol. 3, ed LA Roche-sur-Yon (France: Springer), 77-99. doi: 10.1007/10_2015_332

Duruibe, J. O., Ogwuegbu, M. O. C., and, Egwurugwu, N. J. (2007). Heavy metal pollution and human biotoxic effects. Int. J. Phys. Sci. 2, 112-118. doi: 10.5897/IJPS.9000289

Ebrahiminezhad, A., Taghizadeh, S., Ghasemi, Y., and Berenjian, A. (2018). Green synthesized nanoclusters of ultra-small zero valent iron nanoparticles as a novel dye removing material. Sci. Total Environ. 621, 1527-1532. doi: 10.1016/j.scitotenv.2017.10.076

Eksin, E., Erdem, A., Fafal, T., and Kivçak, B. (2019). Eco-friendly sensors developed by herbal based silver nanoparticles for electrochemical detection of mercury(II) ion. Electroanalysis 31, 1075-1082. doi: 10.1002/elan. 201800776 
Farhadi, K., Forough, M., Molaei, R., Hajizadeh, S., and Rafipour, A. (2012). Highly selective $\mathrm{Hg}^{2+}$ colorimetric sensor using green synthesized and unmodified silver nanoparticles. Sens. Actuat. B Chem. 161, 880-885. doi: 10.1016/j.snb.2011.11.052

Firdaus, M. L., Fitriani, I., Wyantuti, S., Hartati, Y. W., Khaydarov, R., McAlister, J. A., et al. (2017). Colorimetric detection of mercury(II) ion in aqueous solution using silver nanoparticles. Anal. Sci. 33, 831-837. doi: 10.2116/analsci.33.831

Fong, B. M. W., Siu, T. S., Lee, J. S. K., and Tam, S. (2007). Determination of mercury in whole blood and urine by inductively coupled plasma mass spectrometry. J. Anal. Toxicol. 31, 281-287. doi: 10.1093/jat/31.5.281

Gawade, V. V., Gavade, N. L., Shinde, H. M., Babar, S. B., Kadam, A. N., and Garadkar, M. K. (2017). Green synthesis of $\mathrm{ZnO}$ nanoparticles by using calotropis procera leaves for the photodegradation of methyl orange. J. Mater. Sci. Mater. Electr. 28, 14033-14039. doi: 10.1007/s10854-017-7254-2

Gomathi, M., Prakasam, A., Rajkumar, P. V., Rajeshkumar, S., Chandrasekaran, R., and Anbarasan, M. P. (2020). Green synthesis of silver nanoparticles using Gymnema sylvestre leaf extract and evaluation of its antibacterial activity. South Afr. J. Chem. Eng. 32, 1-4. doi: 10.1016/j.sajce.2019.11.005

Guo, C., and Irudayaraj, J. (2011). Fluorescent Ag clusters via a proteindirected approach as a $\mathrm{Hg}(\mathrm{II})$ ion sensor. Anal. Chem. 83, 2883-2889. doi: $10.1021 /$ ac1032403

Hong-Xin, N., Shen-Heng, L., Hong-Ying, L., Yi-Hua, C., Wei-Wei, L., PeiLin, L., et al. (2017). Clinicopathological features, diagnosis, and treatment of IgA nephropathy with minimal change disease related to exposure to mercury-containing cosmetics: a case report. Clin. Nephrol. 87:196. doi: $10.5414 / \mathrm{CN} 108967$

Jarujamrus, P., Amatatongchai, M., Thima, A., Khongrangdee, T., and Mongkontong, C. (2015). Selective colorimetric sensors based on the monitoring of an unmodified silver nanoparticles (AgNPs) reduction for a simple and rapid determination of mercury. Spectr. Acta Part A Mol. Biomol. Spectr. 142, 86-93. doi: 10.1016/j.saa.2015.01.084

Jebril, S., and Dridi, C. (2020). Green synthesis of silver nanoparticles using Melia azedarach leaf extract and their antifungal activities: in vitro and in vivo. Mater. Chem. Phys. 248:122898. doi: 10.1016/j.matchemphys.2020.122898

Kailasa, S. K., Chandel, M., Mehta, V. N., Park, J. T. (2018). Influence of ligand chemistry on silver nanoparticles for colorimetric detection of $\mathrm{Cr}^{3+}$ and $\mathrm{Hg}^{2+}$ ions. Spectr. Acta Part A Mol. Biomol. Spectr. 195, 120-127. doi: 10.1016/j.saa.2018.01.038

Kamali, K. Z., Pandikumar, A., Jayabal, S., Ramaraj, R., Lim, H. N., Ong, B. H., et al. (2016). Amalgamation based optical and colorimetric sensing of mercury(II) ions with silver@ graphene oxide nanocomposite materials. Microchim. Acta 183, 369-377. doi: 10.1007/s00604-015-1658-6

Karunasagar, D., Arunachalam, J., and Gangadharan, S. (1998). Development of a 'collect and punch'cold vapour inductively coupled plasma mass spectrometric method for the direct determination of mercury at nanograms per litre levels. J. Anal. At. Spectrom. 13, 679-682. doi: 10.1039/A8 02132E

Kateshiya, M. R., George, G., Rohit, J. V., Malek, N. I., and Kailasa, K. S. (2020). Ractopamine as a novel reagent for the fabrication of gold nanoparticles: Colorimetric sensing of cysteine and $\mathrm{Hg}^{2+}$ ion with different spectral characteristics. Microchem. J. 158:105212. doi: 10.1016/j.microc.2020. 105212

Kodamatani, H., Matsuyama, A., Saito, K., Kono, Y., Kanzaki, R., and Tomiyasu, T. (2012). Sensitive determination method for mercury ion, methyl-, ethyl-, and phenyl-mercury in water and biological samples using high-performance liquid chromatography with chemiluminescence detection. Anal. Sci. 28, 959-965. doi: 10.2116/analsci.28.959

Koduru, J. R., Kailasa, S. K., Bhamore, J. R., Kim, K.-H., Dutta, T., and Vellingiri, K. (2018). Phytochemical-assisted synthetic approaches for silver nanoparticles antimicrobial applications: a review. Adv. Colloid Interface Sci. 256, 326-339. doi: 10.1016/j.cis.2018.03.001

Lin, Z., Li, X., and Kraatz, B. H. (2011). Impedimetric immobilized DNA-based sensor for simultaneous detection of $\mathrm{Pb}^{2+}, \mathrm{Ag}^{+}$, and $\mathrm{Hg}^{2+}$. Anal. Chem. 83, 6896-6901. doi: 10.1021/ac2014096

Link, S., Burda, C., Wang, Z. L., and El-Sayed, A. M. (1999). Electron dynamics in gold and gold-silver alloy nanoparticles: the influence of a nonequilibrium electron distribution and the size dependence of the electron-phonon relaxation. J. Chem. Phys. 111, 1255-1264. doi: 10.1063/1.479310
Liu, X., Tang, Y., Wang, L., Zhang, J., Song, S., Fan, C., et al. (2007), Optical detection of mercury(II) in aqueous solutions by using conjugated polymers and label-free oligonucleotides. Adv. Mater. 19, 1471-1474. doi: 10.1002/adma.200602578

Lu, Y., Li, X., Wang, G., and Tang, W. (2013). A highly sensitive and selective optical sensor for $\mathrm{Pb}^{2+}$ by using conjugated polymers and label-free oligonucleotides. Biosens. Bioelectr. 39, 231-235. doi: 10.1016/j.bios.2012.07.045

Meng, X., Cao, D., Hu, Z., Han, X., Li, Z., and Ma, W. (2018). A highly sensitive and selective chemosensor for $\mathrm{Pb}^{2+}$ based on quinoline-coumarin. RSC Adv. 8, 33947-33951. doi: 10.1039/C8RA04935A

Naseem, K., Begum, R., Wu, W., Irfan, A., Al-Sehemi, A. G., and Farooqi, H. Z. (2019). Catalytic reduction of toxic dyes in the presence of silver nanoparticles impregnated core-shell composite microgels. J. Clean. Prod. 211, 855-864. doi: 10.1016/j.jclepro.2018.11.164

Nevado, J. J. B., Martín-Doimeadios, R. C. R., Bernardo, F. J. G., and Moreno J. M. (2005). Determination of mercury species in fish reference materials by gas chromatography-atomic fluorescence detection after closed-vessel microwave-assisted extraction. J. Chromatogr. A 1093, 21-28. doi: 10.1016/j.chroma.2005.07.054

Nguyen, T. D., Phan, N. H., Do, M. H., and Ngo, T K. (2011). Magnetic $\mathrm{Fe}_{2} \mathrm{MO}_{4}(\mathrm{M}: \mathrm{Fe}, \mathrm{Mn})$ activated carbons: fabrication, characterization and heterogeneous Fenton oxidation of methyl orange. J. Hazard. Mater. 185, 653-661. doi: 10.1016/j.jhazmat.2010.09.068

Ono, A., and Togashi, H,. (2004). Highly selective oligonucleotide-based sensor for mercury(II) in aqueous solutions. Angew. Chem. Int. Ed. 43, 4300-4302. doi: 10.1002/anie.200454172

Papanikolaou, N. C., Hatzidaki, E. G., Belivanis, S., Tzanakakis, G. N., and Tsatsakis, M. A. (2005). Lead toxicity update. a brief review. Med. Sci. Monitor 11, RA329-RA336.

Paz, S., Rubio, C., Frías, I., Gutiérrez, Á. J., González-Weller, D., Martín, V., et al. (2019). Toxic metals ( $\mathrm{Al}, \mathrm{Cd}, \mathrm{Pb}$ and $\mathrm{Hg}$ ) in the most consumed edible seaweeds in Europe. Chemosphere 218, 879-884. doi: 10.1016/j.chemosphere.2018.11.165

Priya, R. S., Geetha, D., and Ramesh, S. P. (2016). Antioxidant activity of chemically synthesized AgNPs and biosynthesized Pongamia pinnata leaf extract mediated AgNPs-A comparative study. Ecotoxicol. Environ. Saf 134, 308-318. doi: 10.1016/j.ecoenv.2015.07.037

Qing, W., Zhao, M., Kou, C., Lu, M., and Wang, Y. (2018). Functionalization of silver nanoparticles with mPEGylATED LUTEOLIN FOR selective visual detection of $\mathrm{Hg}^{2+}$ in water sample. RSC Adv. 8, 28843-28846. doi: 10.1039/C8RA05243C

Raj, S., Singh, H., Trivedi, R., and Soni, V. (2020). Biogenic synthesis of AgNPs employing Terminalia arjuna leaf extract and its efficacy towards catalytic degradation of organic dyes. Sci. Rep. 10:9616. doi: $10.1038 / \mathrm{s} 41598-020-66851-8$

Rurack, K., and, Resch-Genger, U. (2002). Rigidization, preorientation and electronic decoupling-the 'magic triangle' for the design of highly efficient fluorescent sensors and switches. Chem. Soc. Rev. 31, 116-127. doi: 10.1039/b100604p

Santhosh, A. S., Sandeep, S., and Swamy, K. N. (2019). Green synthesis of nano silver from euphorbia geniculata leaf extract: investigations on catalytic degradation of methyl orange dye and optical sensing of $\mathrm{Hg}^{2+}$. Surfaces Interf. 14, 50-54. doi: 10.1016/j.surfin.2018.11.004

Shah, Z., Hassan, S., Shaheen, K., Khan, S. A., Gul, T., Anwar, Y., et al. (2020). Synthesis of AgNPs coated with secondary metabolites of Acacia nilotica: an efficient antimicrobial and detoxification agent for environmental toxic organic pollutants. Mater. Sci. Eng. C 111:110829. doi: 10.1016/j.msec.2020. 110829

Singh, J., Dutta, T., Kim, K.-H., Rawat, M., Samddar, P., and Kumar, P. (2018). 'Green' synthesis of metals and their oxide nanoparticles: applications for environmental remediation. J. Nanobiotechnol. 16:84. doi: 10.1186/s12951-018-0408-4

Singh, R. K., Mishra, S., Jena, S., Panigrahi, B., Das, B., Jayabalan, R., et al. (2018). Rapid colorimetric sensing of gadolinium by EGCG-derived AgNPs: the development of a nanohybrid bioimaging probe. Chem. Commun. 54, 3981-3984. doi: 10.1039/C8CC01777H

Sumi, M. B., Devadiga, A., Shetty, K. V., and Mb, S. (2017). Solar photocatalytically active, engineered silver nanoparticle synthesis using aqueous extract of 
mesocarp of cocos nucifera (Red Spicata Dwarf). J. Exp. Nanosci. 12, 14-32. doi: 10.1080/17458080.2016.1251622

Tang, L., and Li, J. (2017). Plasmon-based colorimetric nanosensors for ultrasensitive molecular diagnostics. ACS Sens. 2, 857-875. doi: 10.1021/acssensors.7b00282

ul Ain, N., Aslam, Z., Yousuf, M., Waseem, W. A., Bano, S., Anis, I., et al. (2019). Green synthesis of methyl gallate conjugated silver nanoparticles: a colorimetric probe for gentamicin. N. J. Chem. 43, 1972-1979. doi: 10.1039/C8NJ04565H

Umamaheswari, C., Lakshmanan, A., and Nagarajan, S. N. (2018). Green synthesis, characterization and catalytic degradation studies of gold nanoparticles against congo red and methyl orange. J. Photochem. Photobiol. B Biol. 178, 33-39. doi: 10.1016/j.jphotobiol.2017.10.017

Veisi, H., Azizi, S., and Mohammadi, P. (2018). Green synthesis of the silver nanoparticles mediated by Thymbra spicata extract and its application as a heterogeneous and recyclable nanocatalyst for catalytic reduction of a variety of dyes in water. J. Clean. Prod. 170, 1536-1543. doi: 10.1016/j.jclepro.2017.09.265

Wang, G., Su, M.-Y., Chen, Y.-H., Lin, F.-F., Luo, D., and Gao, S. -F. (2006). Transfer characteristics of cadmium and lead from soil to the edible parts of six vegetable species in southeastern China. Environ. Poll. 144, 127-135. doi: 10.1016/j.envpol.2005.12.023

Wang, G. L., Zhu, X. Y., Jiao, H. J., Dong, Y. M., and Li, J. Z. (2012). Ultrasensitive and dual functional colorimetric sensors for mercury (II) ions and hydrogen peroxide based on catalytic reduction property of silver nanoparticles. Biosens. Bioelectron. 31, 337-342. doi: 10.1016/j.bios.2011.10.041

Wang, Y.-T., Hu, S., Zhang, Y., Gong, H., Sun, R., Mao, W., et al. (2018). A colorimetric $\mathrm{Pb}^{2+}$ chemosensor: rapid naked-eye detection, high selectivity, theoretical insights, and applications. J. Photochem. Photobiol. A Chem. 355, 101-108. doi: 10.1016/j.jphotochem.2017.10.027

Wang, Z., Fang, C., and Megharaj, M. (2014). Characterization of iron-polyphenol nanoparticles synthesized by three plant extracts and their fenton oxidation of azo dye. ACS Sustain. Chem. Eng. 2, 1022-1025. doi: 10.1021/sc500021n

Waseem, A., Arshad, J., Iqbal, F., Sajjad, A., Mehmood, Z., and Murtaza, G. (2014). Pollution status of pakistan: a retrospective review on heavy metal contamination of water, soil, and vegetables. Biomed. Res. Int. 2014:813206. doi: $10.1155 / 2014 / 813206$
Wei, H., Li, B., Li, J., Dong, S., and Wang, E. (2008). DNAzyme-based colorimetric sensing of lead $(\mathrm{Pb} 2+)$ using unmodified gold nanoparticle probes. Nanotechnology 19:095501. doi: 10.1088/0957-4484/19/9/095501

Yarur, F., Macairan, J.-R., and Naccache, R. (2019). Ratiometric detection of heavy metal ions using fluorescent carbon dots. Environ. Sci. Nano 6, 1121-1130. doi: 10.1039/C8EN01418C

Yu, J., Wang, X., Kang, Q., Li, J., Shen, D., and Chen, L. (2017). One-pot synthesis of a quantum dot-based molecular imprinting nanosensor for highly selective and sensitive fluorescence detection of 4-nitrophenol in environmental waters. Environ. Sci. Nano 4, 493-502. doi: 10.1039/C6EN00395H

Zhang, X.-F., Liu, Z.-G., Shen, W., and Gurunathan, S. (2016). Silver nanoparticles: synthesis, characterization, properties, applications and therapeutic approaches. Int. J. Mol. Sci. 17:1534. doi: 10.3390/ijms17091534

Zhang, Y., Li, C., Su, Y., Mu, W., and Han, X. (2020). Simultaneous detection of trace $\mathrm{Cd}(\mathrm{II})$ and $\mathrm{Pb}$ (II) by differential pulse anodic stripping voltammetry using a bismuth oxycarbide/nafion electrode. Inorg. Chem. Commun. 111:107672. doi: 10.1016/j.inoche.2019.107672

Zhu, X., Liu, B., Hou, H., Huang, Z., Zeinu, K. M., Huang, L., et al. (2017) Alkaline intercalation of $\mathrm{Ti}_{3} \mathrm{C}_{2}$ MXene for simultaneous electrochemical detection of $\mathrm{Cd}(\mathrm{II}), \mathrm{Pb}(\mathrm{II}), \mathrm{Cu}(\mathrm{II})$ and $\mathrm{Hg}(\mathrm{II})$. Electrochim. Acta 248, 46-57. doi: 10.1016/j.electacta.2017.07.084

Ziemba, S. E., Mattingly, R. R., McCabe M. J. Jr., and Rosenspire, J. A. (2006). Inorganic mercury inhibits the activation of LAT in T-cell receptor-mediated signal transduction. Toxicol. Sci. 89, 145-153. doi: 10.1093/toxsci/kfj029

Conflict of Interest: The authors declare that the research was conducted in the absence of any commercial or financial relationships that could be construed as a potential conflict of interest.

Copyright (C) 2020 Ahmed, Kabir and Xiong. This is an open-access article distributed under the terms of the Creative Commons Attribution License (CC BY). The use, distribution or reproduction in other forums is permitted, provided the original author(s) and the copyright owner(s) are credited and that the original publication in this journal is cited, in accordance with accepted academic practice. No use, distribution or reproduction is permitted which does not comply with these terms. 